Es ist wahrscheinlich, daß dieses Material durch den erhöhten Abbau der pufferunlöslichen RNS geliefert wird.

Die Abnahme der spezif. Aktivität der TMV-RNS mit der Zeit folgt schon aus der Tatsache, daß die Menge des TMV mit der Zeit ansteigt, so daß zu Beginn der später durchgeführten Photosynthesen bereits größere Mengen an nicht radioaktivem TMV in der Pflanze vorliegen.

Abschließend kann noch gesagt werden, daß die erhaltenen Ergeb. nisse mit der Vorstellung im Einklang stehen, daß die TMV-RNS in Kernnähe synthetisiert wird ${ }^{13}$, da die pufferunlösliche ,Pflanzen-NS“ vorwiegend aus Kern-Nukleinsäure bestehen dürfte ${ }^{\text {i4 }}$.

Wir danken Herrn Prof. Dr. E. Broda für sein reges Interesse an dieser Arbeit. Herrn Felix Wehrmann danken wir für technische Hilfe bei der Durchführung der Versuche.

13 R. Engler und G. Schramm, Z. Naturforseh. 15 b, 38 (1960).

14 E. Basler und B. Commoner, Virology 2, 13 (1956).

\title{
Berichtigungen und Zusatz
}

In der Arbeit von R. Riemschneider und H. Kampfer soll es (Mh. Chem., 90, 523) in Zeile 13 v. u. heißen: cis- $\alpha$-Phenylzimtsäurechlorid (nicht: -säureamid).

In der Arbeit von R. Riemschneider und B.E. Grabitz (Mh. Chem. 91) soll auf S. 24, Tab. 1, lfd. Nr. 9 stehen: Spiro [4.2] heptadien, Sdp. 114 ${ }^{\circ}$; ferner soll der Schmp. in FuBnote 18 (Seite 30) $270^{\circ}$ sein (nicht 280 schließlich sind die auf Seite 39 am 30.12. 1959 hinzugefügten Versuche der Arbeit von R. Riemschneider in Mitt. Physiol.-ehem. Inst., Berlin, $\mathbf{R} 18$, vom Juni 1948 entnommen. Auf dieser Seite ist Zeile 23 zu streichen.

Herausgeber: Akademie der Wissensehaften, Wien I, Dr.-Ignaz-Seipel-Platz 2, und Verein Österr. Chemiker, Wien I, Eschenbachgasse 9. - Verlag: Springer-Verlag, Wien I, Mölkerbastei 5. Für den Inhalt verantwortlich: Prof. Dr. F, Kuffner, Wien IX, Währinger Straße 38.

Druck: Adolf Holzhausens Nachfolger, Wien VII, Kandlgasse 19-21 